\title{
Hydroponics Reservoir Temperature Monitoring and Controlling System under Greenhouse Condition
}

\author{
Amy Lizbeth J. Rico
}

\begin{abstract}
An automated reservoir temperature monitoring and controlling system for hydroponic system was developed, calibrated and validated in this study. The automated monitoring and controlling system was developed to monitor and control the reservoir temperature of nutrient solution in hydroponic system. The greenhouse available at the Center for Hydroponics and Aquaponics Technology (CHAT) and locally available materials and hardware for the hydroponics and automation were used in the development of the system. These devices were designed and assembled based on the conceptual framework of the study. The reservoir temperature sensor sends signal to the microcontroller which triggers the turning on/off of water chiller and the mixer. The instruments used were calibrated prior to the performance evaluation and obtained calibration equation for the water temperature sensor is $y=x+0.37$. Validation of the automated reservoir temperature monitoring and controlling system was done and the recorded maximum temperature is $31{ }^{\circ} \mathrm{C}$ and the minimum temperature is $24^{\circ} \mathrm{C}$. The lettuce planted during the validation has an average height of $14.61 \mathrm{~cm}$ and the average leaf count of 12 for the lettuce crops during the $4^{\text {th }}$ week after planting. A total of $4.78 \mathrm{~kg}$ of lettuce crop was harvested with an average of 20.6 grams per lettuce crop was obtained. Based on the performance evaluation and validation done on the automated reservoir temperature monitoring and controlling system, it was found to be reliable. This system becomes useful in reducing labor cost, and allows for real-time monitoring of reservoir temperature, therefore increasing farmers' crop productivity and income.
\end{abstract}

Index Terms: automation, greenhouse, hydroponics, reservoir temperature, sensor

\section{INTRODUCTION}

In the present scenario, almost everything can be controlled and operated automatically, but there are still a few important sectors in our country where automation has not been adopted or not been put to a full-fledged use, perhaps because of several reasons such as cost. Agriculture has been one of the primary occupations of man since early civilizations and even today manual interventions in farming are inevitable. Without automation in hydroponics, many growers spend

Manuscript published on 30 September 2019

* Correspondence Author

Amy Lizbeth J. Rico*, College of Engineering and Technology, Tarlac Agricultural University, Malacampa, Camiling, Tarlac, Philippines 2306

(C) The Authors. Published by Blue Eyes Intelligence Engineering and Sciences Publication (BEIESP). This is an open access article under the CC-BY-NC-ND license http://creativecommons.org/licenses/by-nc-nd/4.0/ approximately 15-30 minutes a day testing and correcting the system levels. This means that beginning growers will often spend more time on testing parameters until the farmers familiarize themselves with the nutrient levels needed. Also, farmers tend to over-correct one or two of the variables. The automated reservoir temperature monitoring and controlling system keeps the system levels stable and provides the optimal environment for the plants which results to bigger and healthier plants.

Hence, this study is conceptualized to develop an automated system by monitoring the reservoir temperature of the nutrient solution in a hydroponic system for optimum plant growth as this factor can greatly affect the growth of lettuce. Specifically, the study aimed to; (1) install an automated reservoir temperature monitoring and controlling mechanism for the nutrient solution, (2) evaluate the performance of the automated monitoring and controlling device, and (3) determine the response of lettuce on the automated monitoring and controlling device

\section{MATERIAL AND METHODS}

\section{A. Conceptualization of the Study}

The conceptual paradigm of the study is presented in Figure 1. The study aimed to monitor and control the reservoir temperature of the nutrient solution using hydroponic system under greenhouse condition. Through this process, time and labor can be saved as well as real time monitoring of the parameters can be achieved.

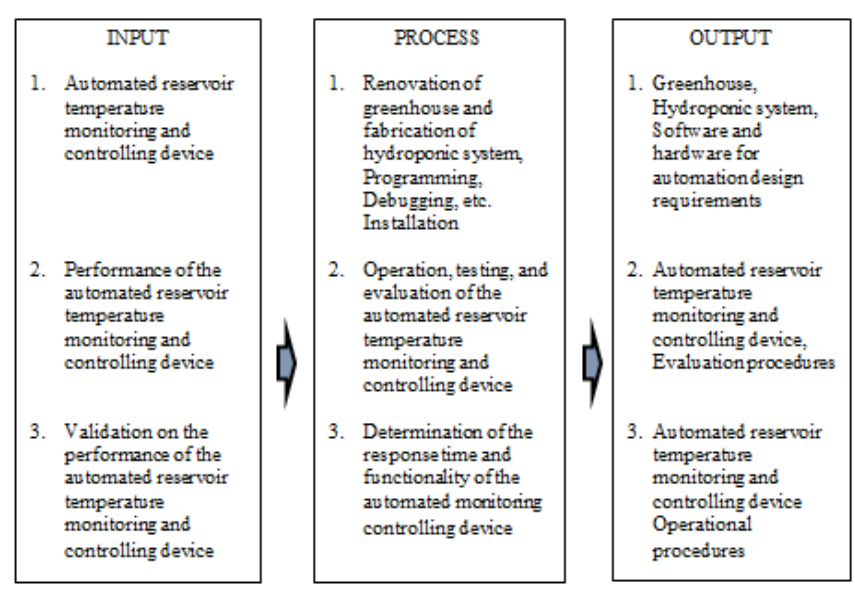

Figure 1. Conceptual framework of the study.

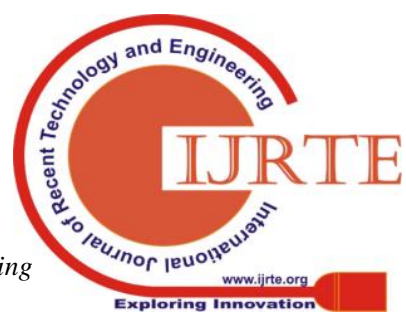




\section{Hydroponics Reservoir Temperature Monitoring and Controlling System under Greenhouse Condition}

\section{B. The Production System}

The automated hydroponic system used in the study is composed of the structural system, the hydroponic system, and the automation system.The automated reservoir temperature monitoring and controlling was tested in one of the greenhouse facilities located at the Center for Hydroponics and Aquaponics Technology (CHAT) measuring 3.0 meters in width, 4.0 meters in length, and 3.5 in meters height. The frames of the greenhouse are made from $2.54 \mathrm{~cm}$ galvanized iron pipes bended and welded together to form a Quonset-type structure. The structure is provided with three roof covers: the insect-proof net in the inner side, the ultraviolet- resistant plastic film in the middle and the gravy woven net shade on the outer side that offers strength and improve aerodynamics to withstand strong wind gust and heavy rains. The available water supply and power supply was used in the operation of the hydroponics system.

The recirculating tube culture system was used in hydroponic system. The hydroponic system was enclosed in the structural system. The grow pipes used was $300.0 \mathrm{~cm}$ in length and $0.075 \mathrm{~cm}$ diameter. A slope of $1 \mathrm{~cm} / 100 \mathrm{~cm}$ of the pipe length was employed for the water to flow through the pipe with ease. The PVC pipes were drilled with $5.08 \mathrm{~cm}$ diameter holes and were spaced at $16.5 \mathrm{~cm}$ between holes (center to center) and made in 2-layer and 4-column pipe layout. A 150 $\mathrm{L}$ reservoir served as the source of water in the hydroponics system where the water was pumped to each growing tubes. The water flow in the hydroponic system was run by a 65-watt submersible pump, 1-2 liters/min flow for each growing tube that lifts the water to the upper layer of the growing tubes. A mixer inside the reservoir was installed to equally dispense the nutrient solution to the reservoir water.

Figure 2 shows the set-up of the automated $\mathrm{pH}$ monitoring and controlling device. The automation system served as the main component of the study and was composed of the controls, sensors, and hardware.

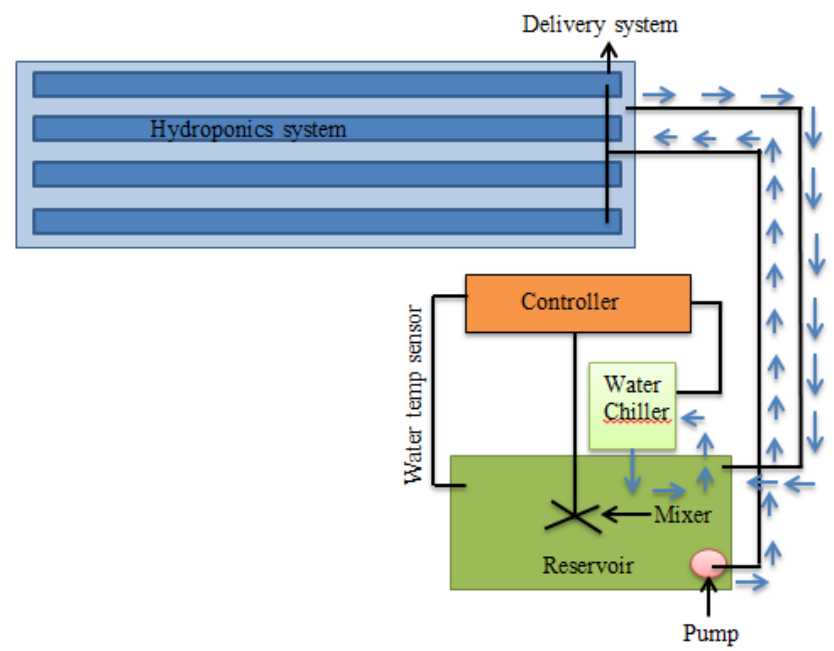

Figure 2. Set-up of the automated reservoir temperature monitoring and controlling device

\section{Automation of the Reservoir Temperature Monitoring and Controlling Device}

The automated reservoir temperature monitoring and controlling device basically monitor and control the temperature of the nutrient solution in a hydroponic system under greenhouse condition. Sensors were used to determine the reservoir temperature in the reservoir. The block diagram shown in Figure 3 is the layout of the hardware design that was used for the automated monitoring and controlling device. A microcontroller using the Arduino platform was used in programming the automation of the reservoir temperature monitoring and controlling device. Using this data, the microcontroller adjusts the temperature of the water in the system by turning on the mixer and the water chiller

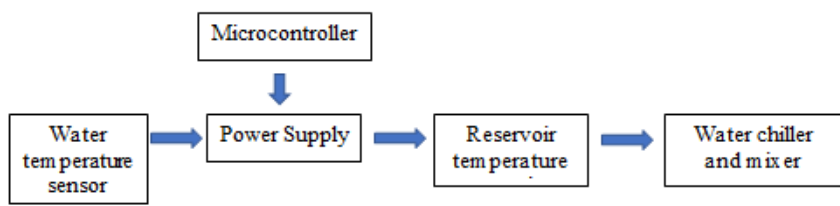

Figure 3. Block diagram of the automated reservoir temperature monitoring and controlling system

Shown in Figure 4 is the flow diagram of the automation used in the study. The LCD is initialized when the automation system is turned on. The reservoir temperature range of $24^{\circ} \mathrm{C}$ $30^{\circ} \mathrm{C}$ for the nutrient solution was entered in the system. These ranges determine when the chiller and the mixer will be turned on. and determined using the water temperature sensor submersed into the reservoir. If the reservoir temperature reading is above $30^{\circ} \mathrm{C}$, the sensor sends signal to the microcontroller to trigger the chiller and the mixer to turn on. When the entered reservoir temperature range is attained, the sensors send signal the microcontroller to turn off the chiller and the mixer.

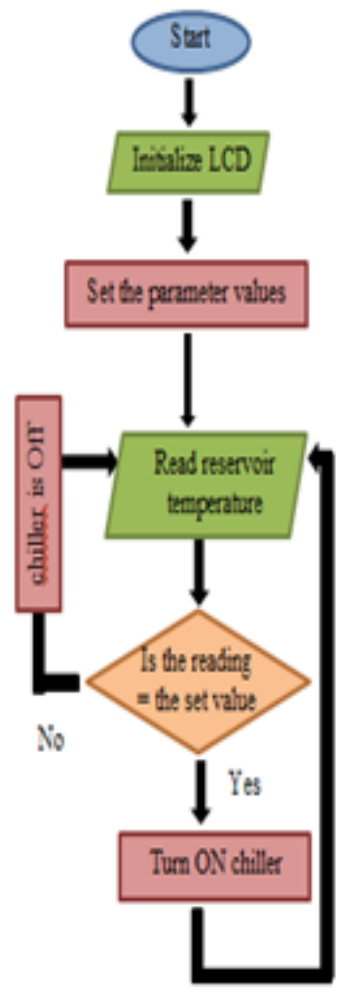

Figure 4. Flow diagram of the automated system

\section{Calibration of the Water Temperature Sensor}

The water temperature sensor was calibrated in order to achieve precision and accuracy.

Published By: 
The hourly reading for 24-hour period in the sensor was compared with the reading from the calibrated instruments. The difference in reading from the sensor and the calibrated instrument were recorded and graphed. Linear regression of the sensor reading and the calibrated instruments was obtained. The equation from the linear regression was inputted into the program for the water temperature sensor.

\section{E. Final Testing}

The reservoir temperature was monitored every day based on their response to the whole system. Automatic turning on of the device when the parameters are beyond the threshold range, response time of the device to be able to attain the threshold range, and automatic turning off of the devices when threshold range is attained were among the data gathered and recorded.

\section{F. Lettuce Production}

The leafy variety of lettuce (Lollo rossa) was used as planting material in the automated hydroponics system as this is commonly used as planting material in hydroponics system. Media composed of carbonized rice hull, sand and rice hull was used as planting media in the automated hydroponics system since these contain most nutrients needed by the plants. The planting cups containing 2-3 lettuce seeds were placed in cups. The cups were placed on individual cut-outs of the growing tubes. The net cups should touch the flowing water in the growing tubes to avoid the plants to be dehydrated. The pump continuously lifts the water and nutrient solution allowing the roots to avail of the nutrients. The reservoir temperature level of the nutrient solution was maintained at a range of $24^{\circ} \mathrm{C}-30^{\circ} \mathrm{C}$ level which is the recommended reservoir temperature level for lettuce production under hydroponics system. At this reservoir temperature level, the needed nutrients were made available to the lettuce plants. These parameters were maintained throughout the growing stage until harvesting stage of the lettuce. The lettuce was harvested 27 days after planting.

\section{G. Validation}

Validation refers to the process of checking that a system meets the specifications and that it fulfils its intended purpose. In the automated hydroponics system, the data gathered from the final testing was analysed and graphed. The automation system was modified to optimize the production system based on the data gathered. Another growing cycle of the lettuce was planted in the automated hydroponics system. Response of the system was monitored from planting to harvesting of the lettuce. The gathered data during validation was compared from the gathered data from the final testing. The differences from the two growing cycle and their relationship was obtained.

\section{RESULTS AND DISCUSSION}

The microcontroller used in the automated hydroponics system is Arduino Mega 2560 which served as the brain of the system and served as the trigger. It also processes the sensor data. Most of the parts were connected to the Arduino using simple jumper wires and the wires were soldered to ensure that they would not get loose. All of the electronic parts were then placed into plastic enclosure to protect delicate electronic parts from dust and moisture.

\section{A. Installation of the Automated Reservoir Temperature Monitoring and Controlling System for Nutrient Solution}

The microcontroller used in the automated hydroponics system is Arduino Mega 2560 which served as the brain of the system and served as the trigger. It also processes the sensor data. Most of the parts were connected to the Arduino using simple jumper wires and the wires were soldered to ensure that they would not get loose. All of the electronic parts were then placed into plastic enclosure (Figure 5) to protect delicate electronic parts from dust and moisture.

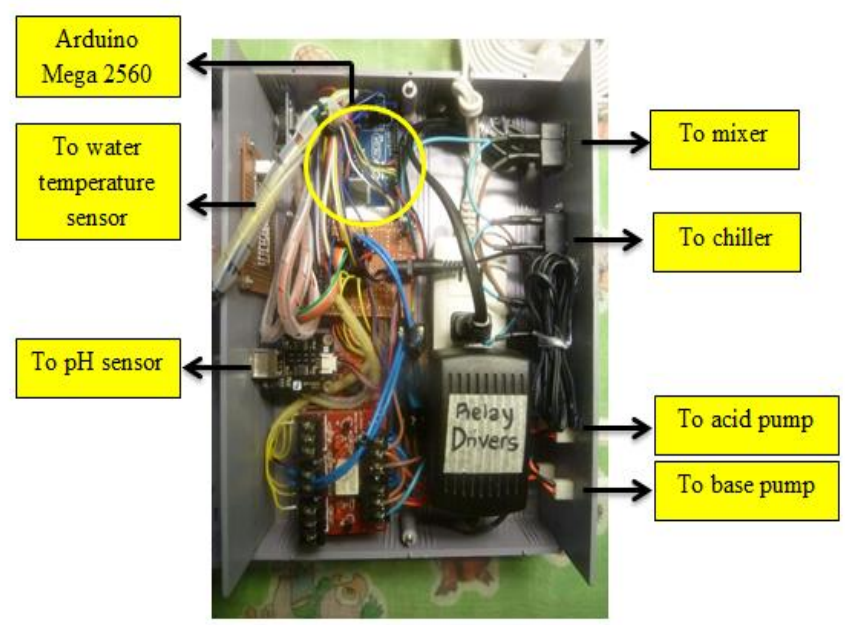

Figure 5. Electronic parts used in the automated hydroponic system

\section{B. Water Temperature Sensor}

The DS18B20 water temperature sensor shown in Figure 6 was used to determine the temperature of the reservoir in the hydroponics systems. The water temperature sensor was submerged to the reservoir and sends trigger signals to the microcontroller to activate the chiller thermostat and the mixer in the reservoir.

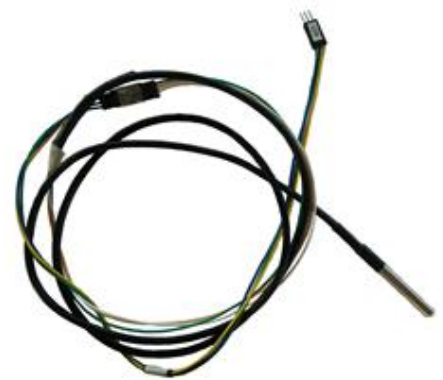

Figure 6. The water temperature sensor used in the study

\section{Calibration of the $\mathbf{p H}$ Monitoring and Controlling} System

Calibration of the reservoir temperature sensor used was done at the Center for Hydroponics and Aquaponics Technology in a 24-hour period before the data gathering. The reading from the sensor and calibrated instrument was obtained, recorded and graphed. 


\section{Hydroponics Reservoir Temperature Monitoring and Controlling System under Greenhouse Condition}

The graph of the calibration for the reservoir temperature sensor is shown in Figure 7. The graphs show linear relationship between the sensor reading and the instrument reading which also obtained an $r^{2}$ of 0.84 . Based on the data gathered, the calibration equation for the reservoir temperature is $y=x+0.37$. This equation was inputted in the program for the automation of the hydroponics system.

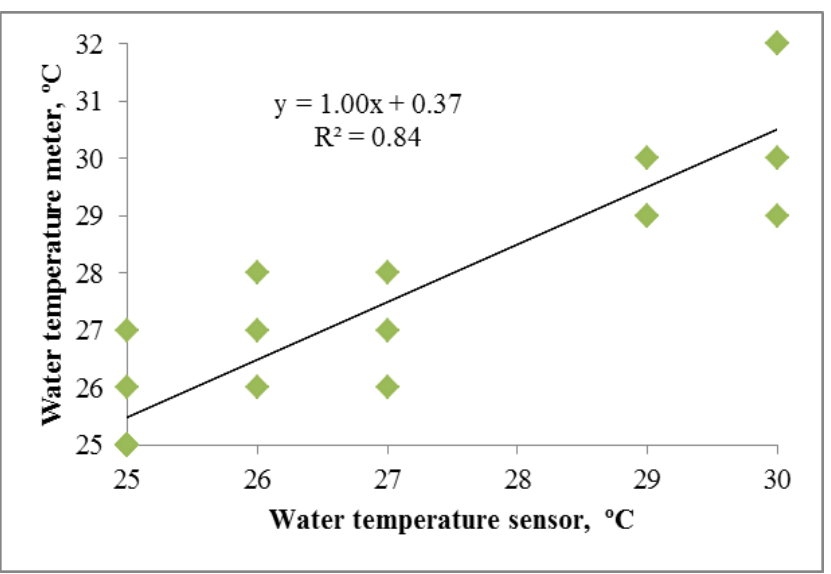

Figure 7. Calibration curve for water temperature sensor

\section{Performance Evaluation}

Based on the results, the obtained maximum reservoir temperature is $31^{\circ} \mathrm{C}$ and minimum is $22^{\circ} \mathrm{C}$. The ability of the system to respond to the set threshold level, the response time of the system to the parameters, and the difference from the calibrated instrument were observed to be able to determine the reliability of the automated hydroponics system. Results showed that turning on of the chiller and mixer when the reading is beyond the threshold range is attained immediately after the reading is beyond the set value in the hydroponics system.

\section{E. Validation of the Automated Reservoir Temperature Monitoring and Controlling System}

During the validation period, the system was observed based on the criteria set for the reservoir temperature of the nutrient solution. Based on the results, the reservoir temperature reading and responses were accepted during the validation. Similar performance of the system during the validation and during the performance evaluation was observed. During the validation of the automated temperature monitoring and controlling system, the growth and number of leaves of the lettuce (test crop) were gathered and recorded weekly and the yield of the lettuce was obtained during harvesting. The lettuce crops obtained a total yield of $4.78 \mathrm{~kg}$ and an average of 20.6 grams per crop.

\section{CONCLUSIONS}

Based on the objectives, the following conclusions were drawn:

1. the installed automated reservoir temperature controller was able to maintain the desired condition for the hydroponic system;

2. based on the observed successes and failures in monitoring the reservoir temperature, the performance of the developed automated reservoir temperature controller was found to be reliable, and;
3. the automated reservoir temperature controlling and monitoring device was able to grow lettuce with yield and responses similar to normal growing conditions.

\section{REFERENCES}

1. Anderson, M. (1989). Understanding Hydroponics. Volunteers in Technical Assistance, Inc. InternationL Journal of Applied Engineering Research. Volume 2.

2. Davis, E. M. \& Kendall, A. D. (2014). The problem of the control system for Greenhouse Climate. Chinese Agricultural Science Bulletin. p154-157.

3. PAES. (2001). Greenhouses. Philippine Agricultural Engineering Standards Volume II. AMTEC, CEAT, UPLB, College, Laguna. Pp. D131 to D150.

4. Rico, A. L. J. (2019). Automated pH and Reservoir Temperature Monitoring and Controlling Systems for Hydroponics Under greenhouse Condition. Disseration. Central Luzon State University. Science City of Munoz, Nueva Ecija.

5. Karat, R. S. (1997). Application of the Wireless Sensor Networks in Agriculture, Transactions of the CSAE. p232-234.

6. Sace, C. F. (2013). Sustainable Agricultural Technologies. CERDS, CLSU, Munoz, Nueva Ecija.

7. Zabeltitz, E. C. (1997). Software Process and Product Improvement, A Historical Perspective, International Journal of Cybernetics, Volume 1, No1, Jan 2003 pp172-197.

\section{AUTHORS PROFILE}

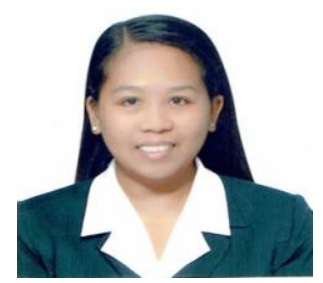

The author was born on March 30, 1984 in Camiling, Tarlac. She is the second among the five children of Mr. Carlos O. Rico and the late Mrs. Estela J. Rico. She finished her elementary education at the Camiling West Central Elementary School in 1996 and took secondary level of education at the Tarlac College of Agriculture-Laboratory School, Camiling, Tarlac in 2000. She earned her Bachelor of Science in Agricultural Engineering degree from the University of the Philippines-Los Baños major in Land and Water Resources Engineering and Technology in 2005 and passed the Licensure Examination for Agricultural Engineer the same year. Months after, she was able to work as an Instructor at the then Tarlac College of Agriculture (now Tarlac Agricultural University). In 2009, she decided to pursue a higher degree and enrolled at the Central Luzon State University under the Master of Science in Agricultural Engineering, blessed to be accepted as one of the scholars in the Engineering Research, Development and Technology of the Department of Science and Technology (DOST-ERDT). Through hard work and dedication, she was able to finish her MS degree in 2014. With her goal to further enhance her skills and competencies, she pursued a $\mathrm{PhD}$ degree program in Agricultural Engineering at CLSU, again, through the Engineering Research and Development for Technology Scholarship Program of the Department of Science and Technology. 